\title{
Namenregister Nr. 13
}

Ein vollståndiger oder gekürzter Abdruck der Referate ist ohne Genehmigung der Redaktion und des Verlages verboten!

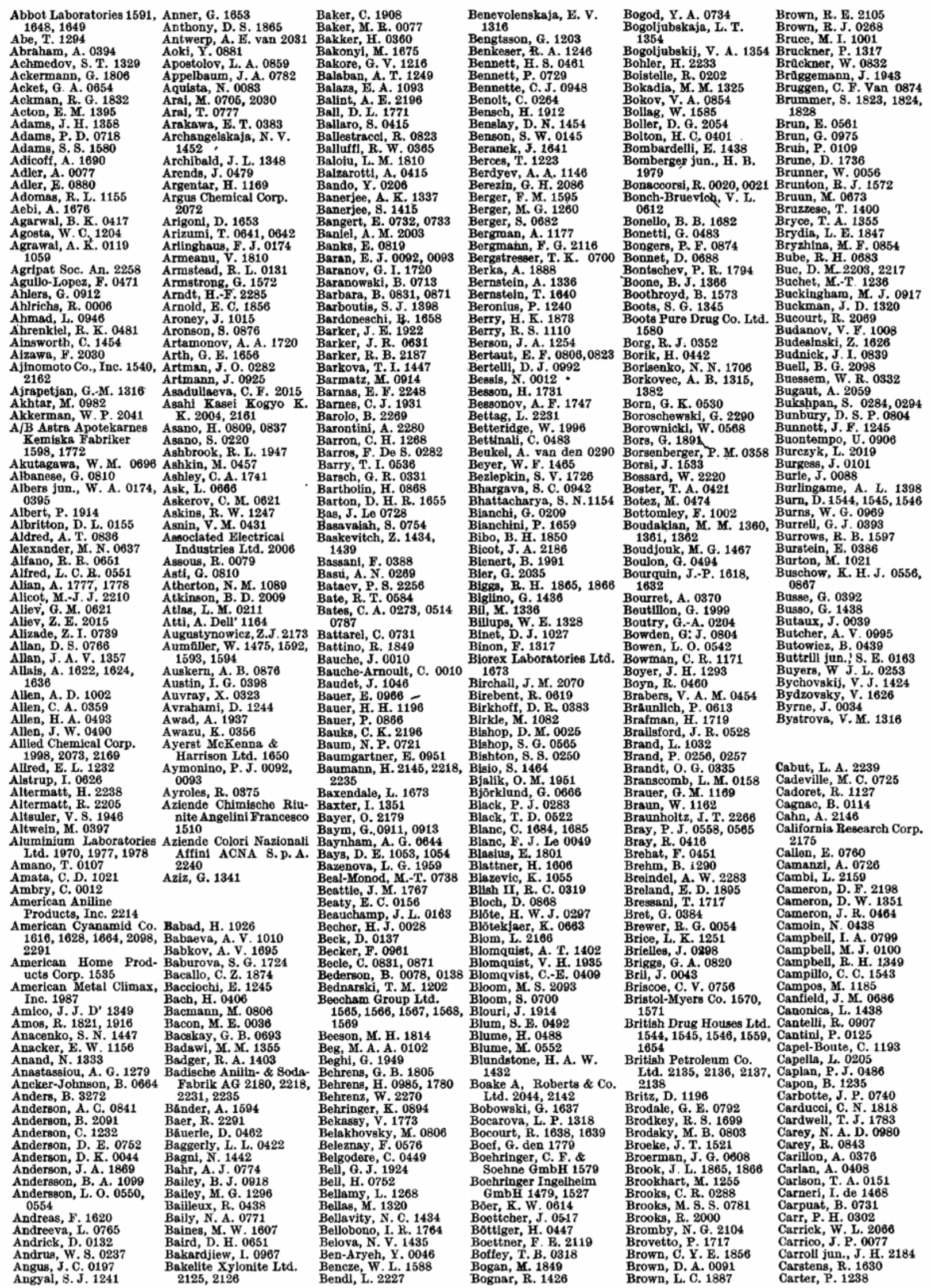




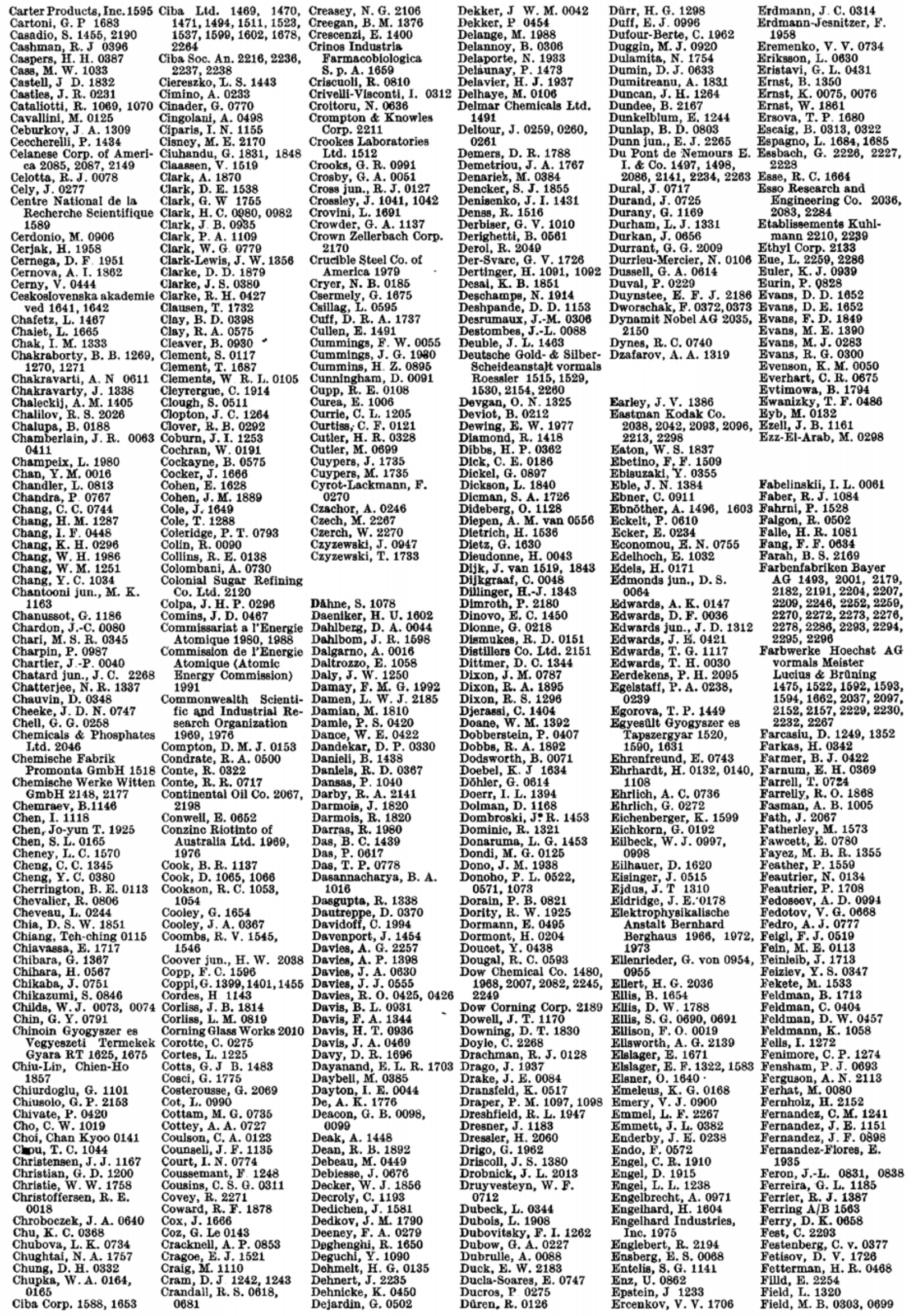




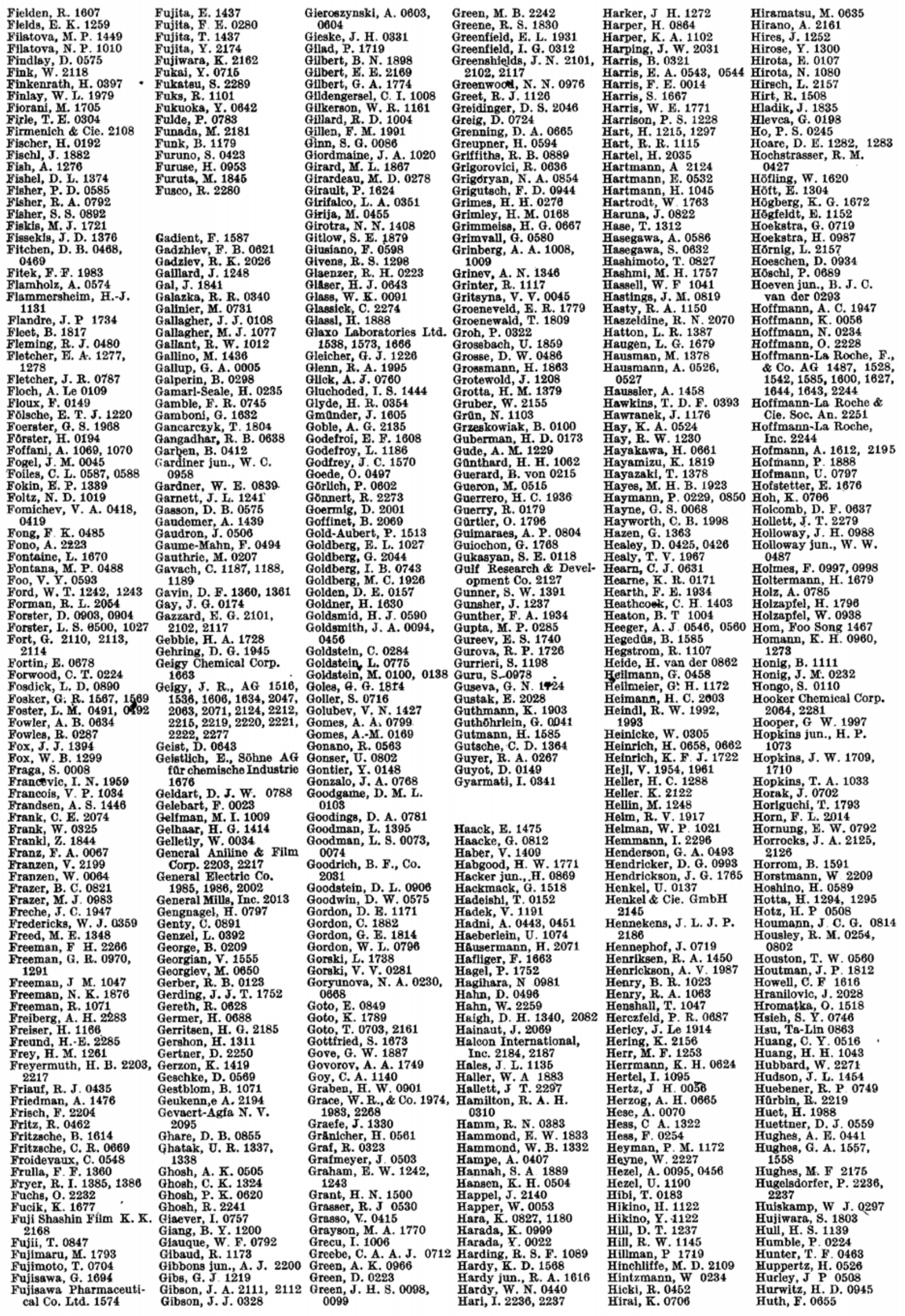




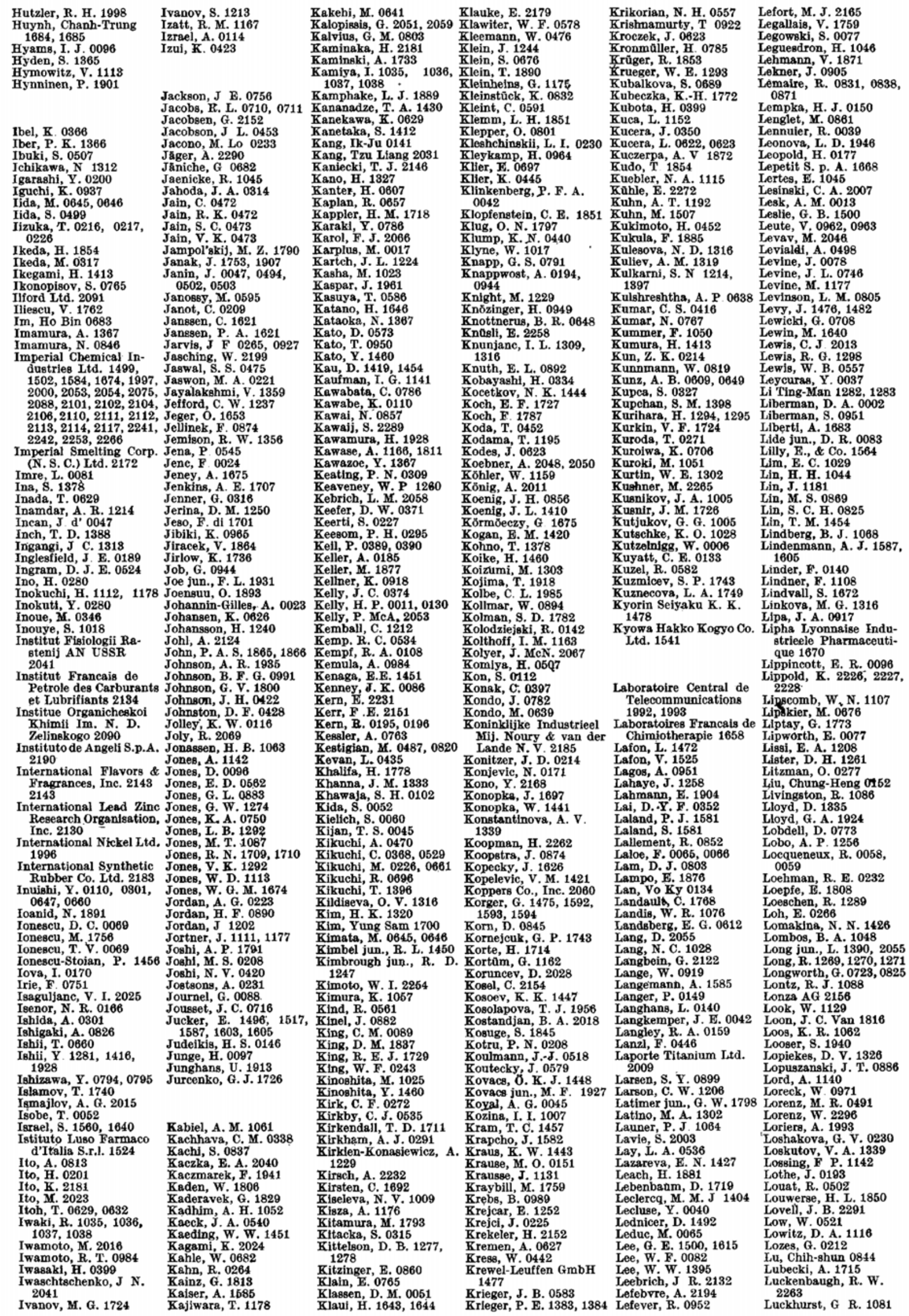




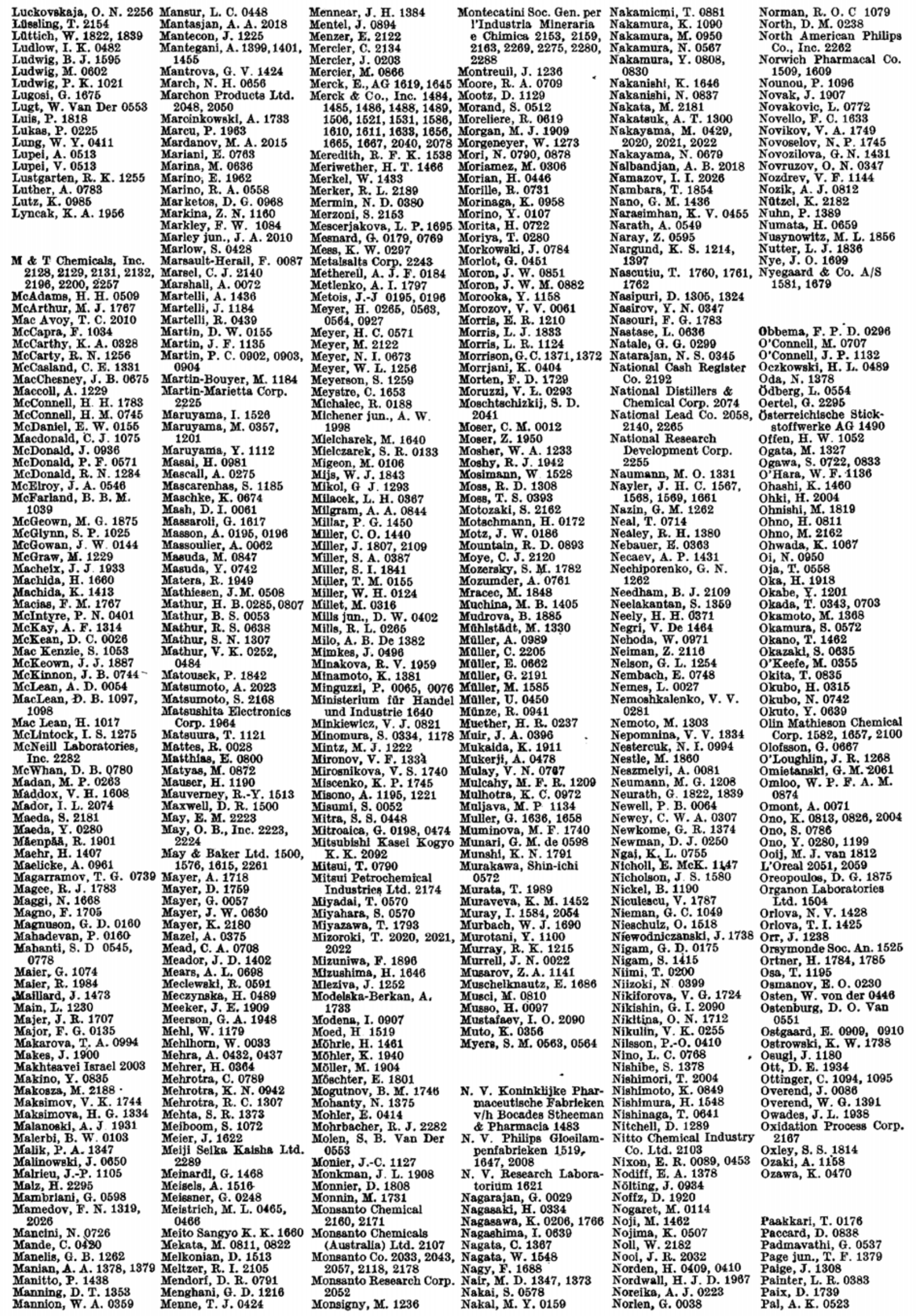




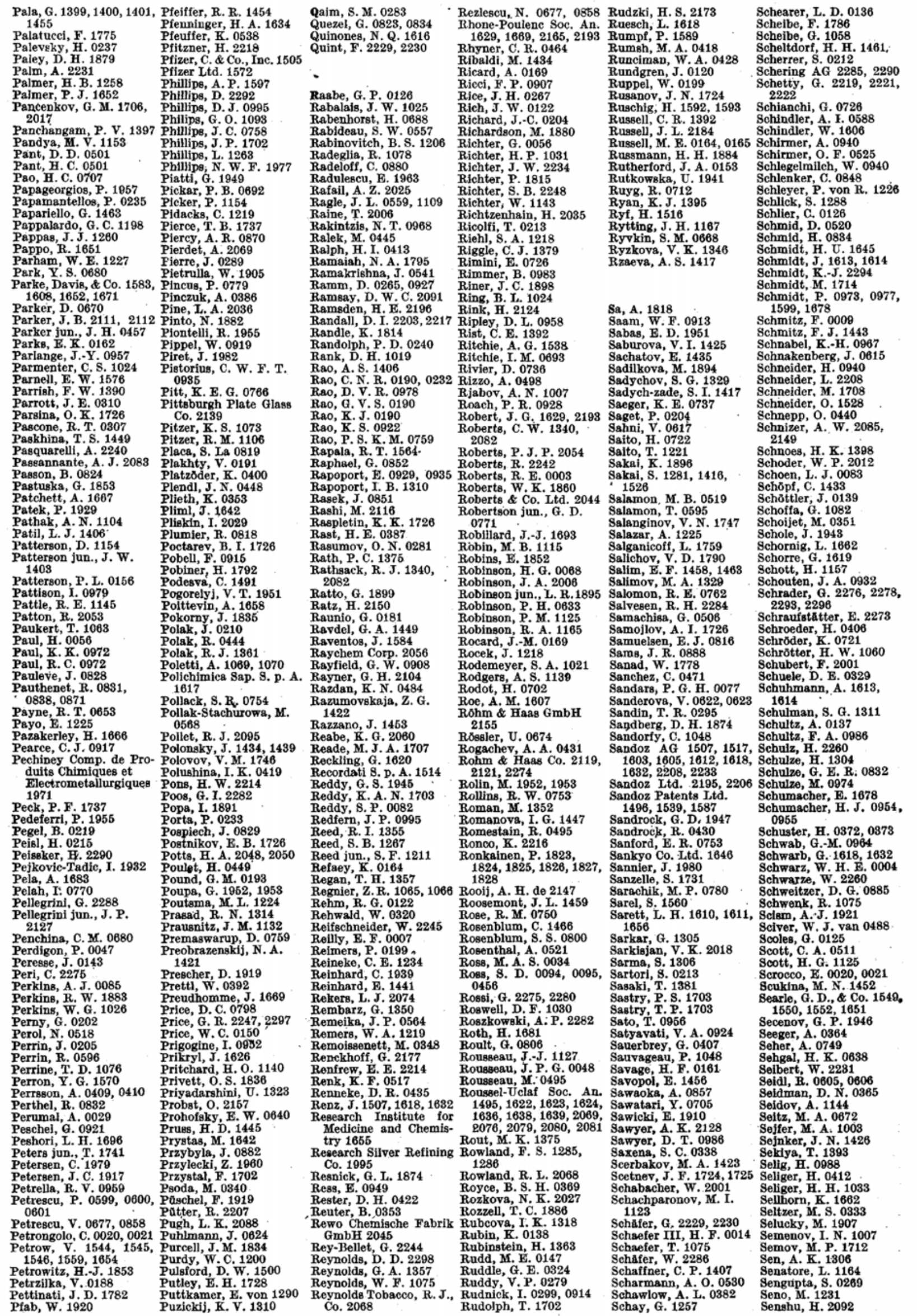




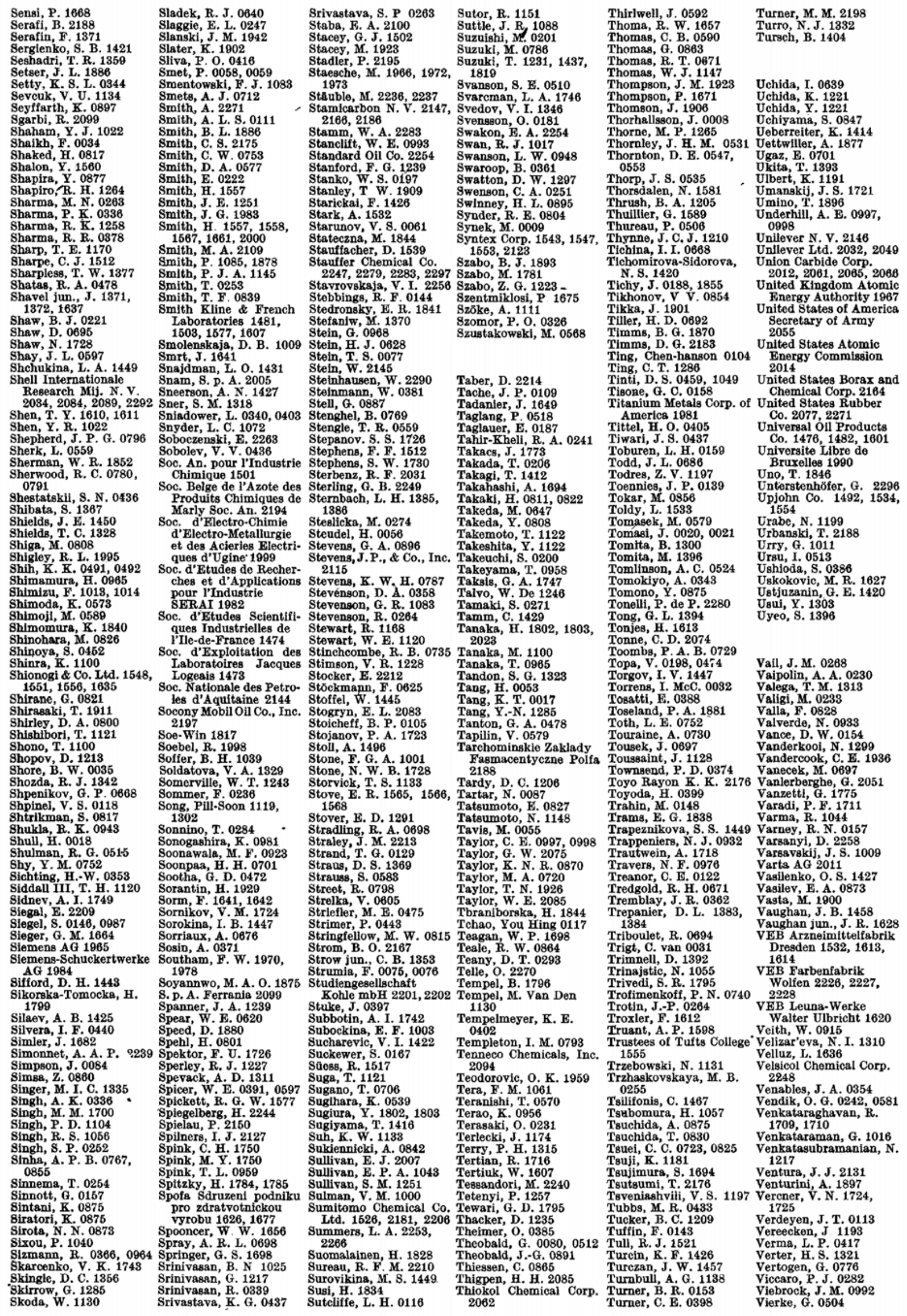




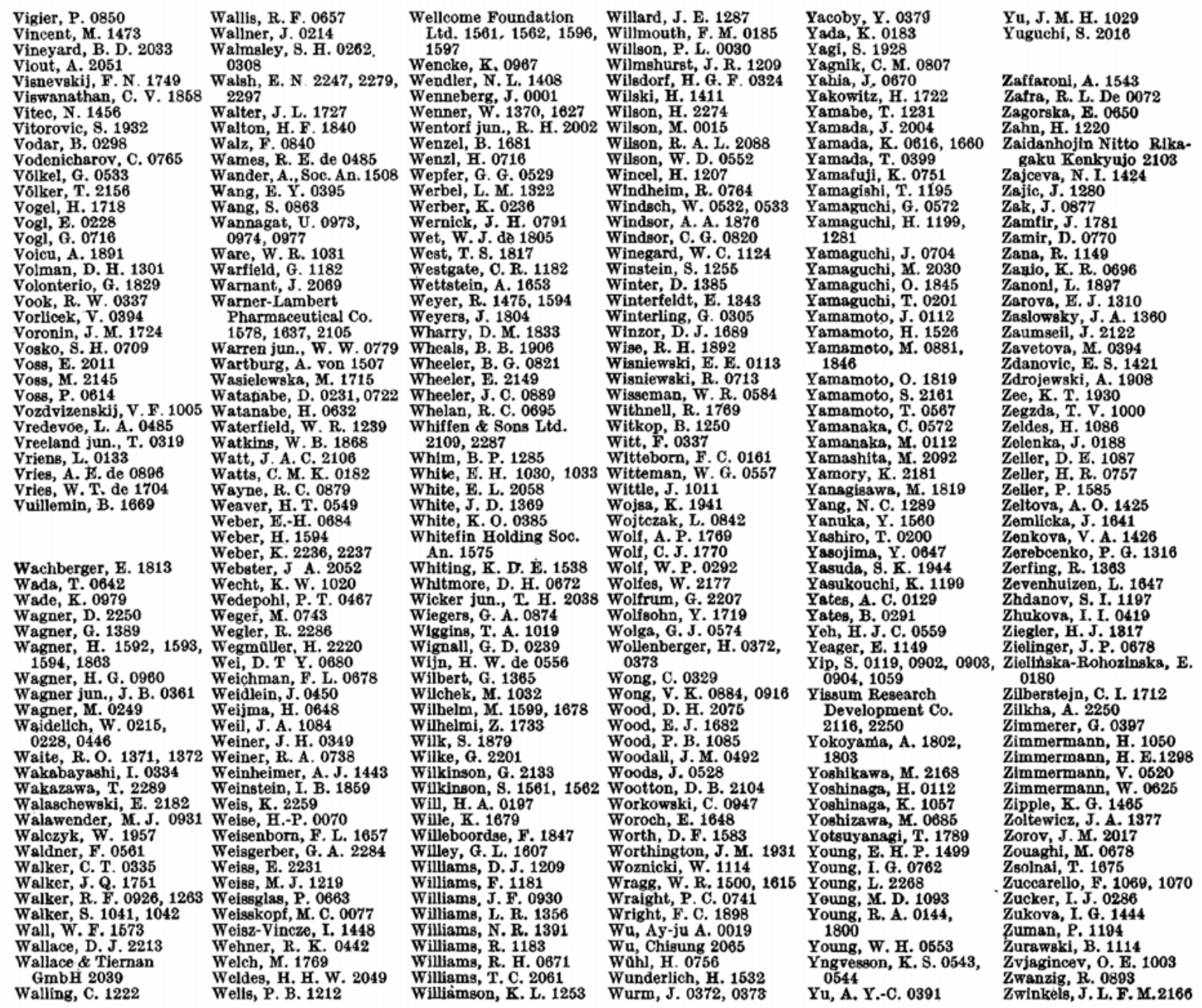

